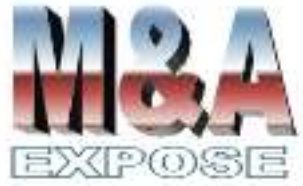

http://jurnal.usahid.ac.id/ index.php/accounting

\section{Pengaruh Orientasi Pelayanan terhadap Komitmen Organisasi di Hotel Sofyan Betawi Jakarta}

\author{
Susy Bhudiharty ${ }^{1}$, lemas Dwi Mutriharti ${ }^{1}$, Levyda ${ }^{1}$
}

\section{Abstrak}

Penelitian ini bertujuan menganalisis pengaruh orientasi pelayanan terhadap komitmen organisasi. Metode analisis yang digunakan adalah analisis regresi linier sederhana. Kuesioner terkait orientasi pelayanan dan komitmen organisasi didistribusikan kepada karyawan Hotel Sofyan Betawi Jakarta. Hasil penelitian menunjukkan bahwa Sofyan Hotel Betawi sudah cukup berorientasi pada pelayanan. Orientasi pelayanan dan komitmen organisasi termasuk kategori cukup tinggi yang berarti karyawan Hotel Sofyan Betawi berkomitmen terhadap orientasi pelayanan dan orientasi pelayanan. Nilai terendah dari variabel orientasi pelayanan terdapat pada indikator pencegahan kegagalan pelayanan. Secara keseluruhan variabel orientasi pelayanan termasuk kategori cukup berorientasi pada pelayanan. Adapun nilai terendah dari variabel komitmen organisasi terdapat pada indicator continuance commitment. Secara keseluruhan variabel komitmen organisasi termasuk kategori cukup komitmen. Kesimpulan menunjukkan adanya pengaruh orientasi pelayanan terhadap komitmen organisasi.

Kata Kunci: Orientasi Pelayanan, Komitmen Organisasi.

\section{Abstract}

This study aims to analyze the influence of service orientation on organizational commitment. The analytical method used is simple linear regression analysis. The questionnaire related to service orientation and organizational commitment was distributed to employees of the Sofyan Betawi Hotel in Jakarta. The results of the study show that Sofyan Betawi Hotel is quite service oriented. Service orientation and organizational commitment include quite high categories, which means Hotel Sofyan Betawi employees are committed to service orientation and service orientation. The lowest value of the service orientation variable is in the service failure prevention indicator. Overall service orientation variables are categorized as quite service-oriented. The lowest value of the organizational commitment variable is in the continuance commitment indicator. Overall the variable organizational commitment includes the category of sufficient commitment. Conclusions indicate the influence of service orientation on organizational commitment.

Keywords : service orientation, organization commitment.

\footnotetext{
${ }^{1}$ Fakultas Ekonomi Universitas Sahid Jakarta susybhudiharty@usahid.ac.id levvda.usahid@gmail.com
} 


\section{PENDAHULUAN}

Meningkatnya jumlah hotel pada tahun 2017, menyebabkan peningkatan dalam persaingan antarhotel itu sendiri. Sebagai penyedia jasa hotel harus mampu memberikan pelayanan yang baik dan maksimal kepada pelanggannya agar mampu bertahan diketatnya persaingan dengan hotel-hotel yang lainnya. Untuk mencapai pelayanan yang maksimal, hotel harus menempatkan orientasi pelayanan sebagai salah satu tujuan utama pelaksanaan pemberian pelayanan. Sebagai salah satu contoh adalah Hotel Sofyan Betawi yang merupakan hotel yang berkonsep syariah, di mana semua kegiatan pelayanan maupun fasilitas yang ada berkonsep sesuai dengan ajaran Islam. Berikut adalah data tingkat hunian yang ada di Hotel Sofyan Betawi di tahun 2016 dan 2017.

\begin{tabular}{|c|c|c|c|}
\hline Bulan & $2016(\%)$ & $2017(\%)$ & Selisih \\
\hline Januari & 34,17 & 62,51 & 28,34 \\
\hline Februari & 39,89 & 79,14 & 39,25 \\
\hline Maret & 49,02 & 68,23 & 19,21 \\
\hline April & 57,44 & 71,79 & 14,35 \\
\hline Mei & 68,36 & 72,61 & 4,25 \\
\hline Juni & 63,56 & 57,36 & $(6,2)$ \\
\hline Juli & 50,33 & 43,91 & $(6,42)$ \\
\hline Agustus & 60,60 & 74,89 & 14,29 \\
\hline September & 63,22 & 61,30 & $(1,92)$ \\
\hline Oktober & 63,77 & 59,47 & $(4,3)$ \\
\hline November & 73,82 & 52,13 & $(21,69)$ \\
\hline Desember & 70,76 & 60,54 & $(10,22)$ \\
\hline Rata-rata & 57,91 & 63,66 & 5,75 \\
\hline
\end{tabular}

Sumber : Manajemen Hotel Sofyan Betawi, 2018.

Dari tabel 1 bisa dilihat tingkat hunian hotel dari tahun 2016-2017 mengalami kenaikan sebesar 5,75 persen. Hal ini mengindikasikan bahwa hotel ini masih menjadi salah satu pilihan untuk menginap bagi konsumen yang ingin menginap di sekitar daerah Tebet. Hotel ini memiliki visi misi yang sangat jelas dalam menerapkan syariat Islam. Adapun visi misi tersebut dapat dilihat pada Tabel 2 berikut :

Tabel 2. Visi dan Misi Hotel Sofyan Betawi

\begin{tabular}{l} 
VISI: \\
Menjadi Hotel terdepan kelas dunia. \\
\hline MISI: \\
1. Menjalankan dan mengembangkan produk dan jasa \\
yang halal, maslahat, memberikan manfaat optimal \\
(best value for the money), dan disukai yang \\
menjadi pilihan utama untuk semua. \\
2. Mengoptimalkan tingkat pengembalian investasi dan \\
tingkat pertumbuhan yang berkesinambungan. \\
3. Mengembangkan kerja sama waralaba dan \\
pengelolaan hotel dengan investor, pemilik hotel, \\
dan operator hotel lainnya. \\
Sumber : Manajemen Hotel Sofyan Betawi, 2017.
\end{tabular}

Sumber : Manajemen Hotel Sofyan Betawi, 2017. 
Dengan Visi dan Misi yang tertera pada Tabel 2 tersebut dapat dilihat bahwa Hotel Sofyan Betawi menempatkan Pelayanan sebagai dasar Visi dan Misi.

Penelitian ini ingin menganalisis sejauh mana orientasi perusahaan pada pelayanan, maka dari itu dilakukan wawancara kepada karyawan yang ada di hotel Sofyan Betawi untuk mengetahui hal tersebut. Hasil wawancara, karyawan menyatakan bahwa perusahaan sudah berorientasi kepada pelayanan karena di dalam dunia jasa perhotelan karena hal ini merupakan salah satu hal terpenting di industri hospitaliti khususnya hotel. Selain itu juga ada peraturan-peraturan yang sudah berorientasi ke dalam pelayanan tersebut dan peraturan itu juga harus dijalankan oleh karyawan. Perihal peraturan-peraturan itu juga mereka berpendapat bahwa peraturan tersebut sudah tertera di dalam nilai-nilai perusahaan dan ada juga di dalam prosedur kerja mereka. Manajer selalu mengingatkan karyawan untuk selalu berorientasi kepada pelayanan melalui kepala setiap departemen yang ada, setelah itu para kepala departemen menyampaikan kepada karyawan melalui morning briefing yang selalu dilaksanakan setiap pagi sebelum memulai pekerjaan. Namun, walaupun sudah berorientasi kepada pelayanan masih saja ada keluhan yang disampaikan oleh tamu. Hal ini disebabkan masing-masing konsumen memiliki harapan yang berbeda terhadap pelayanan yang mereka inginkan.

Orientasi pelayanan yang baik kepada pelanggan akan berjalan sesuai dengan yang diharapkan oleh manajemen dan konsumen jika manajemen dan karyawan hotel mempunyai komitmen terhadap pelayanan agar mereka bisa menempatkan diri dan melakukan pekerjaannya dengan sepenuh hati dan bisa menghasilkan kinerja yang baik.

\section{TINJAUAN PUSTAKA}

Rahadian et al. (2008) menerangkan bahwa konsep orientasi pelayanan dapat dikembangkan pada level individu karyawan maupun level organisasi. Pada level individu orientasi pelayanan dipertimbangkan sebagai aspek untuk mengukur kepribadian. Oleh karenanya beberapa karyawan di organisasi akan lebih berorientasi pelayanan dibandingkan dengan yang lain. Lebih lanjut Rahadian et al. (2008) menjelaskan orientasi pelayanan pada tingkat individu dapat didefinisikan sebagai sekumpulan sikap dan perilaku yang mempengaruhi kualitas interaksi antara karyawan organisasi dengan pelanggan mereka. Sementara itu pada level organisasi, orientasi pelayanan merupakan suatu karateristik desain internal seperti struktur organisasi, suasana, dan budaya pada level organisasi.

Kekuatan bisnis jasa adalah harus selalu memperhatikan kebutuhan dan keinginan pelanggan. Dengan memperhatikan kebutuhan dan keinginan pelanggan, kita dapat memberikan kualitas pelayanan yang lebih baik sepanjang waktu. Kualitas pelayanan yang lebih baik inilah yang kemudian akan berkontribusi pada tingkat kepuasan pelanggan. Jadi, hubungan yang berfokus pada pelanggan, kualitas pelayanan, dan tingkat kepuasan merupakan rangkaian kegiatan yang tidak boleh dipisahkan (Rangkuti, 2016).

Seperti pada umumnya, orientasi pelayanan diuji sebagai susunan yang diterima sebagai kebijakan, praktik, dan prosedur atau karateristik desain internal (Rahadian et al., 2008). Orientasi pelayanan diukur dengan menggunakan hasil penelitian dari Lytle et al. (1998). Skala pengukuran dapat diringkas menjadi sepuluh dimensi sebagai berikut (Lynn dan Lytle et al., 2000) : 


\section{Service Vision}

Merupakan suatu komunikasi berkelanjutan mengenai visi pelayanan pada suatu organisasi. Visi ini menguatkan pentingnya kepuasan pelanggan dan kualitas jasa dalam menciptakan nilai yang superior untuk organisasi. Sebuah top-down service vision merupakan hal penting dan perlu ditanamkan di antara anggota organisasi dalam penyebaran aspirasi untuk memberikan pelayanan yang berkualitas (Rahadian, 2008).

\section{Servant Leadership}

Merupakan presepsi karyawan mengenai contoh yang diberikan manajemen dalam memberikan pelayanan untuk diikuti oleh setiap karyawan yang akan mneguatkan kegiatan pelayanan yang lebih tinggi. Para manajer yang semakin berorientasi pelayanan akan semakin memungkinkan karyawannya menjadi lebih berorientasi pelayanan pada saat mereka berhadapan dengan pelanggan. Servant Leaders merupakan contoh perangkat pelayanan yang menarik dibanding hanya mendikte kebijakan pelayanan untuk organisasi (Rahadian, 2008).

\section{Customer Treatment}

Merupakan persepsi karyawan tentang bagaimana mereka percaya unit mereka dapat menangani konsumen mereka. Organisasi secara konsisten terlibat dalam praktik yang menetapkan golden rule selama menangani konsumen akan menciptakan presepsi positif dari konsumen terhadap kinerja pelayanan (Rahadian, 2008).

\section{Employee empowerment}

Merupakan persepsi karyawan tentang bagaimana meningkatkan kebebasan atas tugas dan wewenang yang mereka terima. Karyawan yang memiliki kebebasan lebih dapat membuat keputusan yang akan memberikan manfaat bagi konsumen secara langsung daripada harus menunda melayani konsumen sampai mendapat izin manajemen (Heskett, 1987).

\section{Service Rewards}

Merupakan persepsi karyawan mengenai apakah perilaku pelayanan dihargai dalam organisasi mereka. Banyak sarjana dan para penulis populer setuju bahwa elemen yang penting pada kualitas jasa adalah hubungan antara kompensasi dan hasil pelayanan (Heskett et al., 1990). Pelayanan mengarahkan organisasi mengenali dan memberi penghargaan pada pemenuhan jasa dengan jelas.

\section{Service Training}

Merupakan persepsi karyawan mengenai berapa banyak pelatihan jasa di organisasi mereka. Penanganan jasa yang sukses adalah yang secara signifikan merupakan hasil dari pelatihan karyawan (Chase and Bowen, 1991; Schesinger and Heskett, 1991). Menurut Schlesinger and Heskett (1991), organisasi jasa yang sukses adalah organisasi yang berinvestasi di teknologi. Secara umum, mereka memandang teknologi sebagai alat untuk mendukung usaha para pekerja sebagai pengganti mereka (Rahadian, 2008).

\section{Service Technology}

Merupakan persepsi karyawan mengenai pemanfaatan teknologi yang disediakan organisasi untuk menyampaikan pelayanan yang baik. Keunggulan teknologi dapat membantu pencapaian superior customer value (Treacy dan Wiersema, 1993). 


\section{Service Failure Prevention}

Merupakan persepsi karyawan tentang perluasan mengenai kemampuan organisasi untuk mencegah kegagalan pelayanan dari hanya berpegang pada perencanaan yang terorganisasi ke sistem perluasan pencegahan (Chase and Bowen, 1991).

9. Service Failure Recovery

Merupakan persepsi karyawan mengenai strategi organisasi saat berhadapan dengan masalah pelayanan yang ada. Berry et al, (1994) berpendapat bahwa jika organisasi gagal dalam memecahkan masalah pelanggan, sesungguhnya mereka telah mengecewakan pelanggan dua kali, pertama ketika kegagalan awal dan kedua saat tidak berhasil dalam mengoreksi penyebab kegagalan. Riset menyatakan bahwa respon segera dan terencana untuk kegagalan pelayanan dapat memungkinkan organisasi untuk mempertahankan 95 persen pelanggannya ketika pelanggannya tidak puas (Albrecht and Zemke, 1985).

10. Service Standards Communication

Merupakan persepsi karyawan mengenai kemampuan organisasi untuk mengkomunikasikan apa yang diharapkan dari karyawan mengenai praktif standar jasa dan perilaku. Tingkat kualitas jasa yang tinggi dicapai oleh organisasi yang mengukur, mengontrol, dan mengkomunikasikan standar kualitas pelayanan (Chase and Bowen, 1991).

Berdasarkan latar belakang masalah dan tinjauan pustaka tersebut, dirumuskan hipotesis bahwa orientasi pelayanan berpengaruh terhadap komitmen organisasi.

\section{METODE}

Penelitian ini menggunakan data primer dari persepsi karyawan Hotel Sofyan Betawi. Populasinya adalah seluruh karyawan yang berjumlah 75 orang karyawan tetap dan kontrak. Teknik samplingnya adalah purposive sampling, di mana penentuan sampel berdasarkan kriteria tertentu. Dalam hal ini kriteria yang ditetapkan adalah karyawan tetap, dengan asumsi karyawan tetap memiliki pemahaman terbaik mengenai orientasi pelayanan dan komitmen organisasi yang diterapkan di Hotel Sofyan Betawi. Berdasarkan kriteria purposive sampling tersebut, maka sampel responden adalah sejumlah 45 orang.

Adapun operasionalisasi variabel independen dan variabel dependen yang digunakan dalam penelitian ini adalah sebagai berikut :

Tabel 3. Operasionalisasi Variabel

\begin{tabular}{ccc}
\hline Variabel & Dimensi & Indikator \\
\hline \multirow{3}{*}{$\begin{array}{c}\text { Komitmen } \\
\text { Organisasi }\end{array}$} & $\begin{array}{c}\text { Affective } \\
\text { Commitment }\end{array}$ & $\begin{array}{c}\text { Keterkaitan emosional dengan organisasi } \\
\text { Memiliki rasa keterlibatan dalam } \\
\text { mencapai misi perusahaan }\end{array}$ \\
\cline { 2 - 3 } & $\begin{array}{c}\text { Continuace } \\
\text { Commitment }\end{array}$ & $\begin{array}{c}\text { Takut merasa rugi jika meninggalkan } \\
\text { perusahaan }\end{array}$ \\
\cline { 2 - 3 } & $\begin{array}{c}\text { Normative } \\
\text { Commitment }\end{array}$ & $\begin{array}{c}\text { keterkaitan untuk terus berada dalam } \\
\text { organisasi }\end{array}$ \\
\hline
\end{tabular}




\begin{tabular}{|c|c|c|}
\hline Variabel & Dimensi & Indikator \\
\hline \multirow{10}{*}{$\begin{array}{l}\text { Orientasi } \\
\text { Pelayanan }\end{array}$} & Service Vision & $\begin{array}{c}\text { Komunikasi berkelanjutan mengenai Visi } \\
\text { Pelayanan }\end{array}$ \\
\hline & $\begin{array}{l}\text { Servant } \\
\text { Leadership }\end{array}$ & Contoh teladan dari pimpinan \\
\hline & $\begin{array}{l}\text { Customer } \\
\text { Treatment }\end{array}$ & $\begin{array}{c}\text { Peraturan-Peraturan yang memaksa } \\
\text { karyawan }\end{array}$ \\
\hline & $\begin{array}{c}\text { Employee } \\
\text { Empowerment }\end{array}$ & $\begin{array}{c}\text { Kebebasan karyawan dalam menciptakan } \\
\text { pelayanan yang baik. }\end{array}$ \\
\hline & Service Rewards & $\begin{array}{l}\text { Pelayanan mengarahkan organisasi } \\
\text { mengenali dan memberi penghargaan } \\
\text { pada pemenuhan jasa yang jelas }\end{array}$ \\
\hline & Service Training & $\begin{array}{l}\text { Pelatihan jasa yang diterima oleh } \\
\text { karyawan }\end{array}$ \\
\hline & $\begin{array}{l}\text { Service } \\
\text { Technology }\end{array}$ & $\begin{array}{l}\text { Pemanfaatan teknologi yang disediakan } \\
\text { perusahaan }\end{array}$ \\
\hline & $\begin{array}{l}\text { Service Failure } \\
\text { Prevention }\end{array}$ & $\begin{array}{l}\text { Mengenai kemampuan organisasi untuk } \\
\text { mencegah kegagalan pelayanan }\end{array}$ \\
\hline & $\begin{array}{l}\text { Service Failure } \\
\quad \text { Recovery }\end{array}$ & $\begin{array}{l}\text { Strategi organisasi saat berhadapan } \\
\text { dengan masalah pelayanan }\end{array}$ \\
\hline & $\begin{array}{l}\text { Service Standard } \\
\text { Communication }\end{array}$ & $\begin{array}{c}\text { Kemampuan Organisasi untuk } \\
\text { mengkomunikasikan apa yang diharapkan } \\
\text { karyawan }\end{array}$ \\
\hline
\end{tabular}

Metode analisis yang digunakan dalam penelitian ini adalah analisis regresi linier sederhana, uji t dan uji koefisien determinasi. Analisis regresi linier sederhana merupakan metode untuk mengukur pengaruh satu variabel independen terhadap variabel dependen, pada derajat kebebasan tertentu. Dalam penelitian ini digunakan derajat kebebasan lima persen pada uji t, sehingga jika nilai signifikansinya di bawah 0,05 maka koefisien regresi adalah signifikan, dan sebaliknya. Adapun uji koefisien determinasi mengukur seberapa kuat variabel independen berkontribusi menentukan variabel dependen.

\section{HASIL DAN PEMBAHASAN}

Hasil analisis variabel orientasi pelayanan pada Hotel Sofyan Betawi dapat dicermati pada tabel 4 berikut :

Tabel 4. Rekapitulasi Hasil Analisis Orientasi Pelayanan

\begin{tabular}{|c|c|c|c|c|}
\hline No & Pernyataan & Skor & Rata-rata Nilai & Kategori \\
\hline 1 & $\begin{array}{c}\text { Visi dan Misi perusahaan sudah } \\
\text { menekankan pelayanan yang baik } \\
\text { kepada pelanggan. }\end{array}$ & 157 & 3.49 & Setuju \\
\hline 2 & $\begin{array}{c}\text { Pemimpin memberikan contoh teladan } \\
\text { yang baik dalam melayani pelanggan. }\end{array}$ & 155 & 3.44 & Setuju \\
\hline
\end{tabular}




\begin{tabular}{|c|c|c|c|c|}
\hline No & Pernyataan & Skor & Rata-rata Nilai & Kategori \\
\hline 3 & $\begin{array}{c}\text { Peraturan-peraturan yang ada di hotel } \\
\text { menuntut karyawan untuk selalu } \\
\text { mengutamakan pelayanan yang baik. }\end{array}$ & 156 & 3.46 & Setuju \\
\hline 4 & $\begin{array}{c}\text { Budaya hotel sudah menekankan } \\
\text { pelayanan yang baik kepada pelanggan. }\end{array}$ & 143 & 3.17 & Cukup Setuju \\
\hline 5 & $\begin{array}{c}\text { Perusahaan memberikan insentif dan } \\
\text { penghargaan kepada karyawan melalui } \\
\text { pelayanan yang baik. }\end{array}$ & 125 & 2.78 & Cukup Setuju \\
\hline 6 & $\begin{array}{c}\text { Nilai inti perusahaan sudah menekankan } \\
\text { pelayanan yang baik kepada pelanggan. }\end{array}$ & 141 & 3.13 & Cukup Setuju \\
\hline 7 & $\begin{array}{c}\text { Teknologi di hotel sudah cukup baik } \\
\text { untuk mendukung pemberian pelayanan } \\
\text { yang baik kepada pelanggan. }\end{array}$ & 128 & 2.84 & Cukup Setuju \\
\hline 8 & $\begin{array}{c}\text { Karakter serta filosofi produk dan } \\
\text { pelayanan di hotel sudah menekankan } \\
\text { pelayanan yang baik kepada pelanggan. }\end{array}$ & 124 & $\mathbf{2 . 7 5}$ & Cukup Setuju \\
\hline 9 & $\begin{array}{c}\text { Strategi pemecahan masalah di hotel } \\
\text { sudah menekankan pelayanan yang baik } \\
\text { kepada pelanggan. }\end{array}$ & 132 & 2.93 & Cukup Setuju \\
\hline 10 & $\begin{array}{c}\text { SOP yang ada di hotel sudah } \\
\text { menekankan pada pelayanan yang baik } \\
\text { kepada pelanggan. }\end{array}$ & 175 & $\mathbf{3 . 8 8}$ & Setuju \\
\hline & \begin{tabular}{c} 
Total \\
\hline
\end{tabular} & 1.436 & 3,19 & Cukup Setuju \\
\hline
\end{tabular}

Sumber : data diolah, 2018.

Berdasarkan Tabel 4 tersebut, indikator pernyataan yang memiliki nilai paling tinggi adalah poin 10; Standard Operating Procedure yang ada di hotel sudah menekankan pada pelayanan. Maka karyawan Hotel Sofyan Betawi memiliki orientasi pelayanan yang baik dan masih bisa ditingkatkan lagi menjadi sangat baik. Adapun indikator paling rendah terdapat pada karakter serta filosofi produk dan pelayanan di hotel yang sudah menekankan pelayanan yang baik kepada pelanggan. Manajemen perlu memberikan pelatihan untuk memperbaiki dan menanamkan mindset karyawan sesuai dengan filosofi produk dan pelayanan.

Adapun hasil analisis variabel komitmen organisasi pada Hotel Sofyan Betawi dapat dicermati pada tabel 5 berikut :

Tabel 5. Hasil Analisis Komitmen Organisasi

\begin{tabular}{|c|c|c|c|c|}
\hline No & Pernyataan & Skor & Rata-rata Nilai & Kategori \\
\hline 1 & $\begin{array}{l}\text { Saya merasa bahwa permasalahan } \\
\text { yang ada di perusahaan menjadi } \\
\text { permasalahan saya juga. }\end{array}$ & 146 & 3.24 & $\begin{array}{l}\text { Cukup } \\
\text { Komitmen }\end{array}$ \\
\hline 2 & $\begin{array}{l}\text { Saya merasa senang jika menghabiskan } \\
\text { sisa karir saya di perusahaan ini. }\end{array}$ & 163 & 3.62 & Komitmen \\
\hline 3 & $\begin{array}{l}\text { Saya tidak bisa meninggalkan } \\
\text { perusahaan ini karena takut tidak bisa } \\
\text { mendapatkan kesempatan kerja di } \\
\text { tempat lain. }\end{array}$ & 148 & 3.29 & $\begin{array}{l}\text { Cukup } \\
\text { Komitmen }\end{array}$ \\
\hline 4 & $\begin{array}{l}\text { Saya takut jika saya meninggalkan } \\
\text { perusahaan ini tidak bisa mendapatkan } \\
\text { rekan kerja yang seperti sekarang. }\end{array}$ & 143 & 3.18 & $\begin{array}{l}\text { Cukup } \\
\text { Komitmen }\end{array}$ \\
\hline
\end{tabular}




\begin{tabular}{|c|c|c|c|c|}
\hline No & Pernyataan & Skor & Rata-rata Nilai & Kategori \\
\hline 5 & $\begin{array}{c}\text { Saya merasa perusahaan ini telah } \\
\text { banyak berjasa untuk hidup saya. }\end{array}$ & 146 & 3.24 & $\begin{array}{c}\text { Cukup } \\
\text { Komitmen }\end{array}$ \\
\hline 6 & $\begin{array}{c}\text { Saya merasa bahwa saya belum } \\
\text { memberikan banyak kontribusi bagi } \\
\text { perusahaan ini }\end{array}$ & 150 & 3.33 & $\begin{array}{c}\text { Cukup } \\
\text { Komitmen }\end{array}$ \\
\hline Total & 896 & 3.32 & $\begin{array}{c}\text { Cukup } \\
\text { Komitemen }\end{array}$ \\
\hline
\end{tabular}

Sumber : data diolah, 2018.

Komitmen organisasi pada Hotel Sofyan Betawi secara rata-rata cukup berkomitmen, indikator paling tinggi pada poin saya merasa senang jika menghabiskan sisa karir saya di perusahaan ini. Poin paling rendah terletak pada indikator saya takut jika saya meninggalkan perusahaan ini tidak bisa mendapatkan rekan kerja yang seperti sekarang. Hal ini merupakan modal utama bagi manajemen dan karyawan untuk tetap berkomitmen bahkan meningkatkan komitmen organisasinya.

Analisis regresi linier sederhana dinyatakan dalam Tabel 6 berikut :

Tabel 6. Analisis Linier Regresi Sederhana

\begin{tabular}{lrrrr}
\hline & B & \multicolumn{1}{c}{ Std. Error } & \multicolumn{1}{l}{ t } & \multicolumn{1}{c}{ Sig. } \\
\hline (Constant) & 1.656 & .486 & 3.407 & .001 \\
Orientasi Pelayanan & -.532 & .152 & 3.501 & .001 \\
\hline
\end{tabular}

a. Dependent Variabel : Komitmen Organisasi

Sumber : data diolah, 2018.

Berdasarkan tabel 6 tersebut, maka dapat dicermati bahwa orientasi pelayanan berpengaruh positif signifikan terhadap komitmen organisasi karena nilai signifikansi lebih kecil daripada derajat kebebasan 0,05 . Hal ini bermakna bahwa jika orientasi pelayanan ditingkatkan, maka komitmen organisasi akan semakin meningkat.

Adapun untuk mengetahui seberapa besar kontribusi variabel independen terhadap variabel dependen digunakan analisis Koefisien Determinasi $\left(R^{2}\right)$. Berikut adalah hasil analisis data koefisien deteminasi :

Tabel 7. Analisis Koefisien Determinasi

\begin{tabular}{|c|c|c|c|c|}
\hline Model & $\mathrm{R}$ & R Square & $\begin{array}{l}\text { Adjusted R } \\
\text { Square }\end{array}$ & $\begin{array}{l}\text { Std. Error of the } \\
\text { Estimate }\end{array}$ \\
\hline 1 & $471^{a}$ & 222 & .20 & 324 \\
\hline
\end{tabular}

a. Predictors: (Constant), $x$

Sumber : data diolah, 2018.

Berdasarkan Tabel 7 tersebut, nilai $R^{2}$ sebesar 22,2 persen maka berarti dalam peelitian ini orientasi pelayanan berkontribusi menjelaskan variasi komitmen organisasi sebesar 22,2 persen, sedangkan sisanya sebesar 77,8 persen ditentukan oleh variable-variabel lain yang tidak termasuk dalam penelitian ini. 


\section{KESIMPULAN}

Berdasarkan analisis hasil penelitian dan pembahasan, maka dapat ditarik beberapa kesimpulan sebagai berikut :

1. Variabel orientasi pelayanan pada indikator Service Standars Communication sudah menekankan pelayanan yang baik kepada pelanggan dengan nilai tertinggi rata-rata 3,88 termasuk kategori tinggi. Sedangkan nilai terendah terdapat pada indikator Service Failure Prevention atau pencegahan kegagalan pelayanan dengan rata-rata 2,75 termasuk kategori cukup tinggi. Secara keseluruhan variabel orientasi pelayanan termasuk kategori cukup berorientasi pada pelayanan dengan nilai rata-rata 3,19.

2. Variabel komitmen organisasi pada indikator Affective Commitment dengan nilai ratarata 3,62 termasuk dalam kategori tinggi. Sedangkan nilai terendah terdapat pada indikator Continuance Commitment dengan rata-rata 3,18 termasuk kategori cukup tinggi. Secara keseluruhan variabel komitmen organisasi termasuk kategori cukup komitmen dengan nilai rata-rata 3,32.

3. Orientasi pelayanan berpengaruh positif signifikan terhadap komitmen organisasi. Semakin tinggi orientasi pelayanan, maka semakin tinggi komitmen organnisasi.

\section{DAFTAR PUSTAKA}

Rahadian, Aditya. 2008. Pengaruh Orientasi Pelayanan terhadap Kepuasan Kerja dan Komitmen Organisasi pada Industri Perhotelan (Studi Kasus : Karyawan Hotel Bintang Tiga di Kota Cirebon).

Kasmir. 2017. Customer Service Excellent: Teori dan Praktik. Jakarta : PT Raja Grafindo Persada.

Kasmir. 2016. Manajemen Sumber Daya Manusia (Teori dan Praktik). Jakarta : PT Raja Grafindo Persada.

Hendry, Supartha dan Dewi. 2017. Pengaruh Servant Leadership terhadap Komitmen Organisasional dan Kinerja Pegawai (Studi pada Pegawai Negeri Sipil di RSUD Wangaya Kota Denpasar). E-Jurnal Ekonomi dan Bisnis Universitas Udayana Vol. 6, N0. 2, pp. 2731-2760.

Shinta, Agustina. 2011. Manajemen Pemasaran. Malang : Universitas Brawijaya Press.

Khaerul, Umam. 2010. Perilaku Organisasi. Bandung : CV Pustaka Setia.

Lynn, Lytle and Bobek. 2000. Service Orientation in Transitional Markets : Does it Matter?. Eouropean Journal of Marketing, Vol.34 No. 3/4, pp. 279-298.

Permana Budi, Agung. 2013. Manajemen Marketing Perhotelan. Yogyakarta : CV Andi Offset.

Rangkuti, Freddy. 2016. Customer Care Excellence : Meningkatkan Kinerja Perusahaan melalui Pelayanan Prima plus Analisis Kasus Jasa Raharja. Jakarta : PT Gramedia Pustaka Utama.

Sugiyono. 2014. Metode Penelitian Bisnis (Pendekatan Kuantitatif, Kualitatif, dan R\&D). Jakarta : Alfabeta.

Sujarweni, Wiratna V. 2015. Metodologi Penelitian-Bisnis \& Ekonomi. Yogyakarta : Pustaka Barupress.

Wike dan Meily. 2012. Pengaruh Servant Leadership terhadap Komitmen Organisasi dan Organization Citizenship Behavior. Jurnal Manajemen. Vol 11 No. 2. 